\title{
Intima-Media Thickness Measurement in Children; Techniques and Reference Values
}

\author{
Ramy El Jalbout* \\ Department of Radiology Sainte-Justine hospital, University of Montreal, Canada
}

*Corresponding author: Ramy El Jalbout, Department of Radiology, Radio-Oncology and Nuclear Medicine of the University of Montreal, Montreal, Quebec, Canada.

To Cite This Article: Ramy El Jalbout, Intima-Media Thickness Measurement in Children; Techniques and Reference Values. Am J Biomed Sci \& Res. 2020 - 7(2). AJBSR.MS.ID.001123. DOI: 10.34297/AJBSR.2020.07.001123.

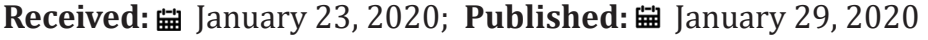

\begin{abstract}
Intima-media thickness (IMT) is a subclinical marker of vascular disease in obese children. There are several techniques for measuring IMT and reference values in children are rare. These references depend on the technique (B mode or radio-frequency ultrasound) and on how IMT is measured (manually, semi-automatic or automatic). IMT varies with age. The IMT values across age in the same pediatric population and according to the different techniques do not exist in the literature. It is therefore not accurate to extrapolate from adult data and it is difficult today to decide whether an IMT value in an obese child is normal or high.
\end{abstract}

Keywords: Ultrasound, Radio Frequency, Intima-Media Thickness, Children

Abbreviations: IMT: Intima-Media Thickness

\section{Introduction}

Intima-media thickness (IMT) is a subclinical marker of vascular disease in obese children, diabetics and with other conditions predisposing to cardiovascular diseases. It is defined as the arterial wall thickness (frequently the common carotid artery) from the lumen-intima interface to the media-adventitia interface. Before conventional clinical and radiological manifestations (atherosclerotic plaque on Doppler ultrasound), the vascular disease is under diagnosed [1-4]. There are several techniques for measuring IMT and reference values in children are rare. These references depend on the technique (B mode or radio-frequency ultrasound) and on how IMT is measured (manually, semi-automatic or automatic) [5]. The IMT values across age in the same pediatric population and according to the different techniques do not exist in the literature. It is therefore difficult today to decide whether an IMT value in an obese child is normal or high.

\section{IMT and Obesity}

Atherosclerosis begins in childhood, especially in children with risk factors. These risk factors include and are not limited to obesity, dyslipidemia, diabetes, genetic factors, and high fat and sugar diet $[1,3]$. Obese children tend to remain obese as adults. The first stage of the disease is endothelial dysfunction followed by impaired vascular vasodilation and increased intimamedia thickness, fat deposition and ultimately the formation of atherosclerotic plaque. IMT measurement is one of the radiological examinations that can assess the early manifestation of the disease before the formation of atherosclerotic plaques. IMT has been shown to be increased in children with risk factors [6].

\section{Radiological Imaging of IMT}

Since the variability of this thickness depends on the measurement site, the Mannheim consensus has been established [7]. In addition, the Association of European Pediatric Cardiologists (AEPC) has also issued recommendations to standardize the measurement of IMT in the literature [8]. Even with these guidelines, the measurement can still be carried out according to conventional $\mathrm{B}$ mode or radiofrequency ultrasound. The radio-frequency method analyzes raw ultrasound data before post-processing. Theoretically this 
measurement should be more precise. The measurement can be done manually by placing the markers on the screen or semiautomatically by indicating to the software where to measure the IMT. An example of the latter is the semi-automatic M'AthStd software (Metris, Argenteuil, France) method which gives the average of sequential measurements along the vessel wall on a line drawn by the operator in front of the desired vascular wall segment. This line could be of variable length. The software will calculate an average of the thickness along the indicated line (Figure 1).

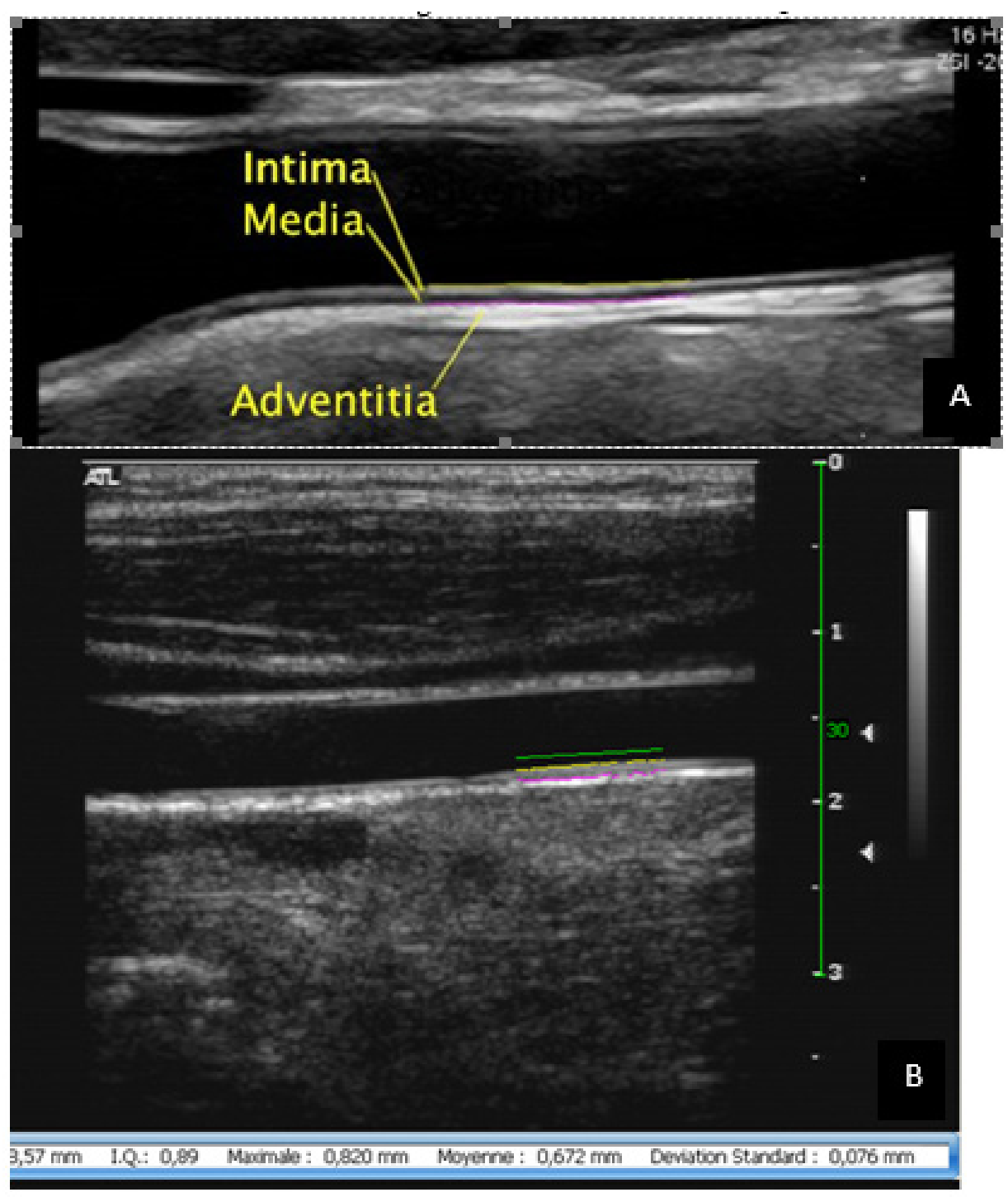

Figure 1: Longitudinal ultrasound view of the common carotid artery. A) shows the intima-media thickness. B) shows the green line drawn by the operator indicating to the automated software where the intima-media thickness is desired to be measured. The average thickness between the yellow and the pink lines is given automatically by the software. I.Q. is Quality Index indicating the percentage of measurements taken into account to calculate the average thickness. The desired Q.I. is at least 0.50 .

\section{Reference Charts}

Doyon et al have published a multicenter study giving normal values of IMT and vascular distensibility of the carotid artery in children. However, this is a manual measurement according to B mode ultrasound [9]. Knowing that IMT is in the range of 0.3 to $0.5 \mathrm{~mm}$, manual measurement has a lot of room for error. In addition, in children the techniques according to B mode and radio-frequency do not correlate [5]. Therefore, we will not be able to radio-frequency extrapolate from these reference tables to decide on a measurement obtained using the radio-frequency method. Jourdan et al did a similar study using B mode ultrasound [10]. Engelen et al. [11] on the other hand, measured according to radio-frequency method [11]. However, their population begins at the age of 15. In summary, there are no studies in pediatrics that used a semi-automatic non-manual method for measuring IMT according to B mode and radiofrequency methods in children under 15 years of age. In the absence of these reference tables, it is difficult to diagnose early vascular disease in children at risk. 


\section{Clinical Perspectives}

Studies of healthy subjects in pediatrics have shown that there is no difference in the measurement of IMT between the right and left sides with regard to the common carotid artery. There is possibly a role of puberty hormones on the cardiovascular system and IMT as evidenced by increased IMT and reduced elasticity after puberty [12]. Several pediatric pathologies affect IMT. These include kidney failure [13], kidney and liver transplantation, Kawasaki disease, diabetes, genetic predisposition, chronic systemic inflammation and dyslipidemia. Obesity, lifestyle and lack of exercise are associated with increased IMT [14] and remain the most common causes of cardiovascular diseases. For the time being, IMT in children is measured mainly in research.

\section{Conclusion}

Age has a very important role in the arterial aging process. Blood pressure also changes with age. Hence, extrapolation from the adult IMT reference tables would not be accurate in pediatrics. For all these reasons, it is important to correlate with custom technique specific reference charts taking into account the age range of children [15,16].

\section{Conflict of Interest}

None.

\section{References}

1. McGill HC Jr, McMahan CA, Zieske AW, Sloop GD, Walcott JV, et al. (2000) Associations of coronary heart disease risk factors with the intermediate lesion of atherosclerosis in youth. The Pathobiological Determinants of Atherosclerosis in Youth (PDAY) Research Group. Arterioscler Thromb Vasc Biol 20(8): 1998-2004.

2. Baker JL, Olsen LW, Sørensen TI (2007) Childhood body-mass index and the risk of coronary heart disease in adulthood. N Engl J Med 357(23): 2329-2337.

3. Raitakari OT, Juonala M, Rönnemaa T, Keltikangas Jarvinen L, Rasanen L, et al. (2008) Cohort profile: the cardiovascular risk in Young Finns Study. Int J Epidemiol. 37(6): 1220-1226.

4. Silva LR, Stefanello JM, Pizzi J, Timossi LS, Leite N (2012) Atherosclerosis subclinical and inflammatory markers in obeseand nonobese children and adolescents. Rev Bras Epidemiol 15(4): 804-816.

5. El Jalbout R, Cloutier G, Roy Cardinal MH, Henderson M, Lapierre C, et al. (2018) Carotid artery inima media thickness measurement in children with normal and increased body mass index: a comparison of three techniques. Pediatric radiology 48(8): 1073-1079.

6. Raitakari OT, Juonala M, Kahonen M, Taittonen L, Laitinen T, et al. (2003) Cardiovascular risk factors in childhood and carotid artery intimamedia thickness in adulthood: The Cardiovascular Risk in Young Finns Study. JAMA 290(17): 2277-2283.

7. Dalla Pozza R, Ehringer Schetitska D, Fritsch P, Jokinen E, Petropoulos A, et al. (2015) Intima media thickness measurement in children: a statement from theAssociation for European Paediatric Cardiology (AEPC) Working Group on cardiovascular prevention endorsed by the Association for European Paediatric Cardiology. Atherosclerosis 238(2): 380-387.

8. Touboul PJ, Hennerici MG, Meairs S, Adams H, Amarenco P, et al. (2012) Mannheim carotid intima-media thickness and plaque consensus (2004-2006-2011): an update on behalf of the advisory board of the 3rd and 4th watching the risk symposium 13th and 15th European Stroke Conferences, Mannheim, Germany, 2004, and Brussels, Belgium, 2011. Cerebrovasc Dis 34(4): 290-296.

9. Doyon A, Kracht D, Bayazit AK, Deveci M, Duzova A, et al. (2013) Carotid artery intima-media thickness and distensibility in children and adolescents: reference values and role of body dimensions. Hypertension 62(3): 550-556

10. Jourdan C, Wuhl E, Litwin M, Fahr K, Trelewicz J, et al. (2005) Normative values for intima-media thickness and distensibility of large arteries in healthy adolescents. J Hypertens. 23(9): 1707-1715.

11. Engelen L, Ferreira I, Stehouwer CD, Boutouyrie P, Laurent S (2013) Reference Values for Arterial Measurements C. Reference intervals for common carotid intima-media thickness measured with echotracking: relation with risk factors. Eur Heart J 34(30): 2368-2380.

12. Bohm B, Hartmann K, Buck M, Oberhoffer R. (2009) Sex differences of carotid intima-media thickness in healthy children and adolescents. Atherosclerosis 206(2): 458-463.

13. Neri S, Signorelli SS, Scuderi R, Bruno M, Bertino G, et al. (2011) Carotid intima-media thickness and liver histology in hemodialysis patients with nonalcoholic Fatty liver disease. Int J Angiol 20(3): 149-156.

14. Ried Larsen M, Grontved A, Moller NC, Larsen KT, Froberg K, et al. (2014) Associations between objectively measured physical activity intensity in childhood and measures of subclinical cardiovascular disease in adolescence: prospective observations from the European Youth Heart Study. Br J Sports Med 48(20): 1502-1507

15. Sass C, Herbeth B, Chapet O, Siest G, Visvikis S, et al. (1998) Intima-media thickness and diameter of carotid and femoral arteries in children adolescents and adults from the Stanislas cohort: effect of age, sex, anthropometry and blood pressure. J Hypertens 16(11): 1593-1602.

16. Stein JH (2009) Carotid ultrasound in children: a window to arterial ageing. Heart 95(8): 611-612. 